\title{
How Does Ethical Leadership Trickle Down? Test of an Integrative Dual-Process Model
}

\author{
Zhen Wang \\ Department of Organization and Human Resources Management \\ Business School, Central University of Finance and Economics \\ 39 South College Road, Haidian District, Beijing, 100081, P.R.China \\ Email: wangzhen@cufe.edu.cn

\begin{abstract}
Haoying Xu
Department of Organization and Human Resources Management Business School, Central University of Finance and Economics 39 South College Road, Haidian District, Beijing, 100081, P.R.China E-mail: xuyingzhongshan@163.com
\end{abstract}

\author{
Yukun Liu* \\ Department of Management and Organization \\ NUS Business School, National University of Singapore \\ B2-03, Biz 2 Building, 1 Business Link, 117592, Singapore \\ E-mail: liuyukun@u.nus.edu
}

*Correspondence concerning this article should be addressed to Yukun Liu, Department of Management and Organization, National University of Singapore.

E-mail: liuyukun@u.nus.edu, Tel: +65-65164879.

\section{Author Statements}

Funding: This study was funded by the National Natural Science Foundation of China (grant number 71302129).

Conflict of Interest: The authors declare that they have no conflict of interest. 
RUNNING HEAD: How Does Ethical Leadership Trickle Down?

How Does Ethical Leadership Trickle Down? Test of an Integrative Dual-Process Model

\begin{abstract}
Although the trickle-down effect of ethical leadership has been documented in the literature, its underlying mechanism still remains largely unclear. To address this gap, we develop a crosslevel dual-process model to explain how the effect occurs. Drawing on social learning theory, we hypothesize that the ethical leadership of high-level managers could cascade to middle-level supervisors via its impact on middle-level supervisors' two ethical expectations. Using a sample of 69 middle-level supervisors and 381 subordinates across 69 sub-branches from a large banking firm in China, we found that middle-level supervisors' ethical efficacy expectation and unethical behavior-punishment expectation (as one form of ethical outcome expectations) accounted for the trickle-down effect. The explanatory role of middle-level supervisors' ethical behavior-reward expectation (as the other form of ethical outcome expectations), however, was not supported. The theoretical and practical implications are discussed.
\end{abstract}

\title{
Keywords
}

ethical leadership; ethical efficacy expectation; ethical outcome expectation; social learning theory 


\section{INTRODUCTION}

Recent years have seen an onslaught of cases relating to corporate fraud and scandals, inflicting great pain on organizations and society. Against this background, an increasing amount of attention has been paid to the topic of ethical leadership in organizational research (Brown and Treviño 2006; Treviño et al. 2014). Being defined as "the demonstration of normatively appropriate conduct through personal actions and interpersonal relationships, and the promotion of such conduct to followers through twoway communication, reinforcement, and decision making” (Brown et al. 2005, p.120), ethical leadership has been found to be positively related to a wide range of beneficial outcomes, including task performance, citizenship behaviors, ethical conducts, and so forth (for systematic reviews, see Bedi et al. 2015; Ng and Feldman 2015). Given these positive outcomes, both researchers and practitioners have engaged in identifying the antecedents of ethical leadership and thus have accumulated a considerable body of evidence (den Hartog 2015; Treviño and Brown 2014). Among several streams of research, there is one suggesting a "trickle-down" effect of ethical leadership, which argues that ethical leadership of high-level leaders could cascade downward and influence the ethical leadership of middle-level supervisors (Mayer et al. 2009; Ruiz et al. 2011a, b; Schaubroeck et al. 2012).

However, these accumulated studies on the trickle-down effect of ethical leadership are limited in a critical way. Although almost all studies have relied on social learning 
theory to explain the mechanisms underlying the effect, none of them has used social learning related constructs to test this account. As noted in a recent article by Sumanth and Hannah (2014, p. 46), "in investigating the effects of ethical leadership of higher level organizational leaders on lower level leaders...though frequently theorized, we are not aware of any research that has actually tested social learning as a mediator in the cascading process". The lack of such research results in an unclear understanding of the intermediate process through which the trickle-down effect occurs. Given this research gap, the current study intends to continue the momentum of research on the trickle-down effect of ethical leadership and advance further to examine its underlying mechanism, aiming to provide a better understanding of how ethical leadership cascades from highlevel managers to middle-level supervisors within an organization.

Specifically, we propose ethical efficacy expectation and ethical outcome expectation ${ }^{1}$ as mediators to disentangle the cascading process of ethical leadership. Social learning theory emphasizes the importance of individual's cognition in the regulation of human behaviors and posits that "most external influences affect behavior through intermediary cognitive processes" (Bandura 1977, p.160). In particular, the changes in efficacy expectation and outcome expectation are the most important intermediate cognitive processes that link external influences to behavioral changes (Bandura 1977; Manz and Sims 1981). Given that our focus is on the ethical realm, we concentrate on ethical efficacy expectation and ethical outcome expectation in the current 
research. Ethical efficacy expectation (i.e., ethical efficacy) refers to “individuals' belief in their ability to mobilize the motivation, cognitive resources, and courses of action necessary to execute ethical behavior" (Mitchell and Palmer 2010, p. 92); ethical outcome expectation represents "individuals' perception of the likelihood that an [ethical/unethical] behavior will lead to a particular [reward or punishment] outcome" (Ashkanasy et al. 2006, p. 450). Social learning theory holds that an individual's efficacy expectation and outcome expectation are susceptible to the influence of role models (e.g., leaders) through a vicarious learning process (Manz and Sims 1981). Thus, it is reasonable to suggest that, the ethical leadership of high-level managers, who oftentimes are regarded as role models, will exert an influence on the ethical efficacy expectation and ethical outcome expectation of middle-level supervisors, which will in turn elicit their ethical leadership behaviors.

We tested our theoretical model using a sample from a large banking firm. Results generally provided support to our hypotheses. By conducting this research, we contribute to the extant literature in three ways. First, this study advances the existing research on the trickle-down effect of ethical leadership by delineating the underlying mechanisms. By considering ethical efficacy expectation and ethical outcome expectation as mediators, the present study provides a direct examination of the trickle-down effect of ethical leadership from the social learning perspective. Second, this study extends the research on ethical efficacy by providing further insights into its nomological network. In 
the early 1990s, Bandura (1991) suggested that moral/ethical beliefs could be applied to ethical situations, suggesting the existence of ethical efficacy. It is only recently, however, that a few studies have formally conceptualized and operationalized this construct and studied its relevance to ethics (Arnaud and Schminke 2012; Hannah and Avolio 2010). Even so, research on ethical efficacy still remains largely in its infancy, and thus warrants further investigation (Hannah et al. 2011). This said, the present study addresses this call and enriches our understanding of ethical efficacy. Third, this study also highlights the role of ethical outcome expectation and advances the literature by contextualizing it in the ethical leadership context (Ashkanasy et al. 2006; Treviño and Youngblood 1990), illuminating another important psychological mechanism that could explain the function of ethical leadership. Taken together, using social learning theory as a theoretical framework, our research aims to answer the question how ethical leadership of high-level managers trickles down to influence the ethical leadership of middle-level supervisors. Our research model is depicted in Figure 1 as shown below.

Insert Figure 1 about here

\section{THEORY AND HYPOTHESES}

\section{Manager Ethical leadership and Supervisor Ethical leadership}

Social learning theory is based on the idea that an individual learns by paying attention to and emulating the attitudes, values and behaviors of role models (Bandura 
1977). As to the learning of ethical conducts in organizations, although individuals can rely on organization's formal regulations or norms to gain ethics-related knowledge, they can also learn ethical conducts via a modeling process, in which they look for role models in the organization and emulate their ethical attitudes, values and behaviors (Brown et al. 2005). This modeling process not only applies to followers who regard their leaders as role models, but also applies to leaders themselves, who also learn from their role models. Indeed, as Brown and Treviño (2006, p. 600) highlighted, "followers are not the only ones who learn from models. Leaders learn from models too. By observing an ethical role model's behavior as well as the consequences of their behavior, leaders should come to identify with the model, internalize the model's value and attitudes, and emulate the modeled behavior". Then it comes to the question who would be leaders' ethical role models. A few studies have answered this question and suggested that top managers or top executives in an organization could serve as ethical role models for middle-level supervisors (see examples in Mayer et al. 2009; Ruiz et al. 2011a). The reasons supporting supervisors as ethical role models for frontline employees, as suggested by existing studies (Brown et al. 2005; Brown and Treviño 2006), could also be extended to the dyadic relationships between high-level managers and middle-level supervisors, in which supervisors become followers of high-level managers. Just like supervisors, having power, status, and the control over the reward/punishment system, as well as having personal characteristics such as being honest and trustworthy, high-level 
managers are legitimate, attractive, and credible to be regarded as ethical role models, from which supervisors could emulate the ethical conducts (Bandura 1977). Based upon the above reasoning as well as the findings in several existing studies (e.g., Mayer et al. 2009; Ruiz et al. 2011a, b, Schaubroeck et al. 2012), we propose the trickle-down effect of ethical leadership of high-level managers on their immediate supervisors'. By using high-level managers, we refer to managers that middle-level supervisors work closely and communicate frequently with, but not those distant top executives. Our rationale is that ethical role modeling is a "side by side" phenomenon (Weaver et al. 2005), and middlelevel supervisors have more chances to observe and imitate ethical behaviors of their intimate leaders (i.e., high-level managers), rather than those of top or executive managers (Brown and Treviño 2014). We propose that:

Hypothesis 1 High-level managers' ethical leadership relates positively to middlelevel supervisors' ethical leadership.

\section{The Mediating Effect of Ethical Efficacy Expectation}

As an ethical cognition (Schaubroeck et al. 2012), ethical efficacy expectation (i.e., ethical efficacy) represents individuals' confidence in their ability to execute ethical behaviors (Hannah and Avolio 2010; Mitchell and Palmer 2010). Unlike the trait-like general efficacy expectation which is more stable, ethical efficacy expectation is more state-like, which indicates that it could be influenced to change. Existing research has found that ethical efficacy expectation is susceptible to external influences (Fischbach 
2015; Hannah and Avolio 2010; May et al. 2013) and could play an important role in ethics-relevant situations (Arnaud and Schminke 2012; Lee et al. 2015). In the present study, we consider ethical efficacy expectation as a crucial factor that contributes to the cascading of high-level managers' ethical leadership. We analyze its role from two aspects as follows.

In one aspect, given that an ethical role model plays a critical role in developing and strengthening one's ethical efficacy beliefs (Bandura 1991), we believe that high-level managers' ethical leadership would exert a positive influence on middle-level supervisors' ethical efficacy expectation. According to the social learning theory, expectations of efficacy are based on four sources of information: performance accomplishments, vicarious experience, verbal persuasion, and emotional arousal, and these four sources could be further influenced by different modes of induction (Bandura 1977). Bandura presented a framework in which many external factors induce sources of efficacy, which in turn impacts efficacy. For instance, he argued that participant modeling, performance desensitization, performance exposure, and self-instructed performance could lead to individuals' performance accomplishments, which in turn increase their efficacy, while suggestions, exhortation, self-instruction, and interpretive treatments are inducements of verbal persuasion, which in turn impacts efficacy. That said, these four sources are not sub-dimensions of efficacy, rather, they are more like the determinants of efficacy and the mechanisms through which external factors influence 
efficacy. In our research, based on this "mode of induction $\rightarrow$ sources of efficacy $\rightarrow$ efficacy" framework, and the function of ethical leadership as the mode of induction (e.g., participant modeling, suggestions), we theorized that ethical leadership would induce individuals' performance accomplishments, vicarious experience, verbal persuasion, and emotional arousal, which would ultimately increase their ethical efficacy.

First, high-level managers' ethical leadership can enhance middle-level supervisors' ethical efficacy expectation through performance accomplishments. Ethical managers set high moral standards and hold their followers accountable for ethical issues through using proactive and effective measures (e.g., using reward systems, conveying ethics-related messages) (Brown et al. 2005). These tactics can ultimately help supervisors to achieve ethical performance and thus enable them to have more opportunities to obtain personal attainment and success in an ethics-related domain. Second, supervisors' ethical efficacy expectation can be enhanced through their own vicarious experience (Bandura 1991). In other words, supervisors can strengthen their ethical efficacy expectation by vicariously observing what others do when being faced with an ethics-related issue. Ethical managers, given their legitimacy, attractiveness and credibility, of course are the role models that supervisors would learn from when facing an ethical issue (Brown et al. 2005). Third, verbal persuasion from ethical managers can ameliorate supervisors' ethical efficacy expectation. Ethical managers usually would discuss business ethics or values openly with their immediate supervisors and encourage them to ask "what is the right 
thing to do" when making decisions (Brown et al. 2005). Through this communication process, ethical managers verbally convey the message to their immediate supervisors that ethical behaviors are appropriate and should be encouraged, hence enhancing supervisors' ethical efficacy expectation (Bandura 1977). Fourth, ethical managers define success not only by outcomes, but also by the ways how the outcomes are achieved. This philosophy helps alleviate followers' affective concerns (e.g., anxiety or stress) that usually relate to outcomes, and thus enables followers to pay more attention to the ethicality of their approaches in achieving goals (Lee et al. 2015; Walumbwa et al. 2011). Additionally, ethical managers expect, appreciate and support their immediate supervisors' ethical behaviors. Such expectations, appreciation and support may make supervisors feel proud and emotionally delighted when exhibiting ethical behaviors, thus enhancing their ethical efficacy expectation. Apart from the above four sources, Hannah and Avolio (2010) recently added another one, which involves providing and articulating organizational support measures that could equip leaders with the confidence to take ethical actions. By setting the ethical tone of the work unit, stressing the importance of ethical behaviors, and using a reward system to incentivize ethical behaviors, ethical managers can establish a social environment that provides the necessary support for their immediate supervisors to adhere to ethical standards and engage in ethical behaviors. Such an ethical social environment could boost supervisors' confidence to behave ethically, thus enhancing their ethical efficacy expectation (Schaubroeck et al. 2012). 
In the other aspect, we propose that enhanced ethical efficacy expectation will motivate middle-level supervisors to exhibit ethical leadership behaviors. According to Bandura (1997), how people behave is better predicted by their beliefs about their capabilities rather than by their actual capabilities. The same logic has also been extended to the realm of moral behavior regulation by Bandura (1991), who contended that ethical efficacy expectation is a critical cognitive process for moral thoughts and behaviors. Ethical efficacy expectation instills in supervisors a sense of confidence in their capabilities to organize and mobilize the cognitive resources to attain moral performance and regulate their behaviors to meet inner moral standards, thus ensuring that they will engage in ethical behaviors even in an ethically adverse situation (Hannah and Avolio 2010; Mitchell and Palmer 2010). Extending to the case of middle-level ethical supervisors, given that they bear the "moral manager" responsibility to hold followers accountable for their ethical/unethical behaviors (Brown et al. 2005), ethical efficacy expectation will be more necessary for supervisors' exhibition of ethical leadership behaviors.

Summarizing the above two aspects of theorizing, we conjecture that ethical efficacy expectation would serve as an intermediate factor linking high-level managers' ethical leadership and their immediate supervisors' ethical leadership. We propose that: 
Hypothesis 2 The relationship between high-level managers' ethical leadership and middle-level supervisors' ethical leadership is mediated by middle-level supervisors' ethical efficacy expectation.

\section{The Mediating Effect of Ethical Outcome Expectation}

Outcome expectation is the other intermediate cognition in social learning theory. Distinguished from efficacy expectation, which represents one's perceived ability to execute a behavior, outcome expectation is one's judgment concerning the likelihood of outcomes resulting from a specific behavior (Manz and Sims 1981). According to Bandura (1977), the consequences of a behavior, which inform individuals about the benefits of an appropriate conduct and the costs of an inappropriate conduct, can facilitate individuals' learning from their role models. Extending this notion to the ethical leadership area, we consider ethical outcome expectation as a key factor in the trickledown process of ethical leadership and argue that high-level managers' ethical leadership can promote their immediate supervisors' ethical leadership through shaping their expectations of ethical outcomes.

According to the social learning perspective, individuals form their ethical outcome expectations through two ways: (1) being rewarded for their own ethical behaviors or punished for their own unethical behaviors (direct learning); (2) observing or hearing about the consequences of others' ethical or unethical behaviors in the workplace (vicarious learning). The latter way, which stresses the role of models in the process of 
learning, is the primary learning approach (Bandura 1977). Having said that ethical leaders would serve as role models for supervisors to learn ethical conducts and given the above arguments on ethical outcome expectations, we reason that ethical managers would play a crucial role in affecting immediate supervisors' ethical outcome expectations. First, being ethical role models for their immediate supervisors, ethical managers would lead them to believe that managers' ethical leadership has been rewarded in the past. Indeed, as Bandura suggested, which was also noted in Weiss (1977), a role model's (i.e., leader) attributes such as status, power, or perceived competence would lead observers (i.e., followers) to believe that the model's behaviors have been rewarded in the past or are appropriate in the situation, and this information would affect observers' expectations that engaging in similar behaviors would lead to eventual rewards. Second, ethical managers will shape immediate supervisors' ethical outcome expectations through rewarding those who behave ethically and punishing those who behave unethically in the workplace (Detert et al 2007). When supervisors observe the consequences of ethical behaviors and unethical behaviors, they will learn what is considered appropriate and inappropriate concerning ethical issues in the organization (Davis and Luthans 1980; Manz and Sims 1981). In other words, these social cues would convey a message to supervisors that behaving ethically is appropriate and will be rewarded, whereas behaving unethically is inappropriate and will be punished (Brown et al. 2005; Brown and Treviño 2006). Accordingly, these outcome expectations would facilitate supervisor's learning in 
an anticipatory ethical manner and influence them to engage in more ethical leadership behaviors.

To summarize, the reasoning above suggests that the relationship between high-level managers' ethical leadership and middle-level supervisors' ethical leadership could be mediated by the ethical outcome expectations of middle-level supervisors. To examine this mediating mechanism in more depth, we further differentiate ethical outcome expectation into two types: ethical behavior-reward expectation, which refers to the perceived likelihood of getting rewards for ethical behaviors; and unethical behaviorpunishment expectation, which refers to the perceived likelihood of getting punished for unethical behaviors. We propose that:

Hypothesis 3 The relationship between high-level managers' ethical leadership and middle-level supervisors' ethical leadership is mediated by middle-level supervisors' ethical behavior-reward expectation.

Hypothesis 4 The relationship between high-level managers' ethical leadership and middle-level supervisors' ethical leadership is mediated by middle-level supervisors' unethical behavior-punishment expectation.

\section{METHOD}

\section{Sample and Procedure}

We collected multilevel and multi-source data from a large banking company in China. This banking company has 120 sub-branches and 976 employees (including front- 
desk clerks and back office staff) in total. At the most basic level of the bank, each subbranch runs independently as a standard operating team that consists of one supervisor (i.e., middle-level supervisor in the organizational hierarchy) and several subordinates. Each sub-branch is under the control of a high-level manager from the corresponding regional branch of the bank. We chose to conduct the research in the banking industry for a few reasons. First, it provides a suitable context for researchers to do ethics-related research. The banking industry is more likely to induce employees to conduct unethical behaviors than other industries because it is characterized by higher stress and less regulation (Ruiz-Palomino et al. 2013). Although ethics in this industry has garnered tremendous public attention and urged government to adopt strict regulation measures, the number of fraud and scandals is still on the rise (Boatright 2010). As ethical leadership has been recognized as an effective way to restrain unethical conduct and elicit ethical behaviors in the banking industry (e.g., Ruiz-Palomino et al. 2011, 2013; Sims and Brinkman 2002; Walumbwa and Schaubroeck 2009), it would be meaningful to examine why and how ethical leadership behavior cascades downward to shape a collective ethical leadership culture in such an industry (Treviño et al. 2003). Second, although most banking firms have ethics-related policies, norms or codes that regulate supervisors' behaviors (Treviño et al. 2003), the boundaries between ethical and unethical behaviors in many banks are still quite vague, which makes supervisors more likely to learn from their direct leaders (i.e., high level managers) about what is right and 
what is wrong in the organization. This said, the cross-level influences of leadership on employees' ethics become very relevant a phenomenon in banking firms. Third, most banking firms have a typical hierarchical structure in which managers in charge of higher-level branches have control over resource allocation, goal setting and reward/punishment system, while supervisors in charge of lower-level branches report directly to these managers. This difference in authority between higher-level managers and lower-level supervisors, along with the frequent interactions between them, meet the prerequisite of social learning process, making the trickle-down effect of ethical leadership possible in the context of banking firms.

Through personal social network and alumni contacts, we approached 79 subbranches. Our research assistants communicated with the branch directors by phone and explained the purpose of the survey in the hope of obtaining their support. Three subbranches refused to participate, resulting in 76 sub-branches that participated. To ensure the effectiveness of the survey, with the branch supervisor' help, we distributed and collected the questionnaires in person. Date collection was conducted during the regular early meeting before business hours. Before completing the questionnaires, all respondents were informed of the research purpose and assured of confidentiality. To reduce common method bias, we administered two different sets of questionnaires, one for sub-branch supervisors and the other one for their subordinates. Specifically, subbranch supervisors reported their perceived ethical leadership of high-level managers, 
their own ethical efficacy expectation and ethical outcome expectation, whereas subordinates reported their perceived ethical leadership of sub-branch supervisors. After completing the survey, each respondent forwarded his or her questionnaire (enclosed in a sealed envelope) to the researchers.

After excluding responses from seven sub-branches with only one or two subordinates, we finally collected a sample of 69 sub-branch supervisors $(57.5 \%$ of all sub-branch supervisors) and 381 subordinates (39.0\% of all employees). In this matched sample, the average number of participating subordinates per sub-branch supervisors was 5.52. Of the 69 supervisors, $47.8 \%$ were women, $81.2 \%$ had a college degree, the average age was 39.61 years $(S D=5.97)$, and the average tenure as a sub-branch supervisor was 2.33 years $(S D=1.22)$. Among the subordinates, $61.9 \%$ were women, $79.0 \%$ had a college degree, the average age was 31.49 years $(S D=6.37)$, and the average dyadic tenure with the supervisor was 2.32 years $(S D=1.14)$.

\section{Measures}

Except for ethical outcome expectation, all other measures in the study were originally in English. Applying the standard translation and back-translation procedure (Brislin 1986), we translated the English scales into Chinese versions. Unless otherwise indicated, the measures were rated by the respondents on a 5-point Likert-type scale. The anchors for the scale were from strongly disagree (1) to strongly agree (5). 
Manager ethical leadership and supervisor ethical leadership. To capture

leadership in the eyes of beholders, we asked followers to rate the ethical leadership behaviors of their immediate leaders. Specifically, high-level manager's ethical leadership was rated by middle-level supervisors (i.e., sub-branch supervisors); middlelevel supervisor's ethical leadership was evaluated by their immediate subordinates. This approach has been used in a number of leadership studies (e.g., Li and Sun 2015; Liu et al. 2012). We used the 6-item version (Detert et al. 2007) of the Ethical Leadership Scale (Brown et al. 2005) in this study (see Appendix). We chose to use this short version instead of the original 10-item version as we found that some of the items (e.g., has the best interests of employees in mind, can be trusted) in the original 10-item scale are redundant and have obvious content overlapping with some other constructs such as consideration and trust, and this has been pointed out by a few recent studies (Mayer et al. 2012; Yukl et al. 2013). We concurred with these studies and believed that we should use the most representative items for ethical leadership in our current study. Sample items for the six-item scale include "My leader defines success not just by results but also by the way that they are obtained" and "My leader disciplines employees who violate ethical standards". As supervisor ethical leadership scores were essentially aggregated based on subordinates' ratings in the multilevel analyses, we calculated the ICC (2) and mean of $R_{\text {wg }}$ for supervisors' ethical leadership, which were .84 and .91 respectively and were above the suggested cutoff point (Bliese 2000; James et al. 1993), supporting the 
aggregation for supervisor ethical leadership in the multilevel analyses. The Cronbach's alphas were .89 for manager ethical leadership and .93 for supervisor ethical leadership.

Ethical efficacy expectation. Ethical efficacy expectation was measured with a 5item Moral Efficacy sub-scale from the Moral Potency Questionnaire (MPQ) developed by Hannah and Avolio (2010) ${ }^{2}$. Sample items include "I am confident that I can confront others who behave unethically to resolve the issue" and "I am confident that I can determine what needs to be done when I face moral/ethical decisions". In the present study, the Cronbach's alpha of the scale was .89 .

Ethical outcome expectation. Since there was no existing scale of ethical outcome expectation in the organizational context, we developed the items based on the theory. Specifically, ethical behavior-reward expectation was measured through three items, including "In our work unit, those who behave ethically will be rewarded", "In our work unit, those who follow ethical standards will be given priority in promotion", and "In our work unit, those who follow ethical principles will be respected by others". Unethical behavior-punishment expectation was measured via another three items, including "In our work unit, those who behave unethically will be punished", "In our work unit, it will be difficult for those who violate ethical standards to get promoted", and "In our work unit, those who violate ethical principles will be despised by others". The anchors for both measures ranged from 1 (very unlikely) to 5 (very likely). The Cronbach's alphas were .90 and .73 respectively. To check the construct validity, we performed exploratory 
factor analysis (EFA) using the principal component method with the number of factors not specified. The results based on oblimin rotation revealed the emergence of two distinct dimensions of ethical outcome expectation, with items loaded nicely on the two proposed factors, without any cross-loadings. The two factors explained $77.22 \%$ of the total variance in ethical outcome expectation.

Control variables. We controlled for middle-level supervisor's age, gender, education and position tenure. Age and position tenure were measured by the number of years. Gender was coded as $1=$ male and $2=$ female. Education was coded into four categories $(1$ = High school or lower, 2 = Associate's degree, 3 = Bachelor's degree, $4=$ Master's degree or higher).

\section{Analysis Strategy}

Given the nested nature of the data, to account for potential non-independence effects, we conducted multilevel modeling to test the hypotheses. Specifically, we tested H1 through hierarchical linear modeling using HLM 6.08 (Raudenbush and Bryk 2002).

Following the recommendations of Hofmann and Gavin (1998), we centered the predictor according to its grand mean in performing these analyses to control for multicollinearity.

To test the cross-level mediation effects (H2-H4), we conducted multilevel path analyses using Mplus 7.0 (Muthén and Muthén 1998-2012). Specifically, we followed the method suggested in Zhang et al. (2009) and estimated the indirect effects based on a 2-21 path-analytical model ( 2 refers to variables at level 2 , while 1 refers to variables at level 
1). To examine the significance of each indirect effect we estimated, we followed Selig and Preacher's (2008) method and conducted a Monte Carlo simulation (i.e., a form of parameter bootstrapping) with 20,000 replications, which provided an estimate of the confidence interval (CI) for each effect.

\section{RESULTS}

\section{Discriminant Validity Tests}

Before hypotheses testing, we conducted a series of confirmatory factor analyses (CFAs) to examine the distinctiveness of the four supervisor-reported variables (manager's ethical leadership, ethical efficacy expectation, ethical behavior-reward expectation, and unethical behavior-punishment expectation). As shown in Table 1, the theorized four-factor model provided an acceptable fit to the data $\left(\chi^{2}=186.32, d f=113\right.$, $\mathrm{CFI}=.93, \mathrm{TLI}=.91, \mathrm{SRMR}=.08)$ and showed a significantly better fit than the threefactor model $\left(\Delta \chi^{2}(3)=73.46, p<.01\right)$, the two-factor model $\left(\Delta \chi^{2}{ }_{(5)}=179.51, p<.01\right)$, and the single factor model $\left(\Delta \chi^{2}{ }_{(6)}=432.75, p<.01\right)$. Given these results, the theorized fourfactor model was superior in fit to all alternative models, and therefore, we can continue to examine these variables as distinct constructs.

Insert Table 1 about here

To provide further support for the discriminant validity of the constructs, we also computed the square root of average variance extracted, another widely used index for 
establishing the discriminant validity of constructs (Fomell and Larcker 1981). As was shown in Table 2, the square root of AVEs for all major constructs in our study were above .81 , which were higher than any of the inter-construct correlations, suggesting that all constructs have good discriminant validity.

\section{Descriptive Statistics}

The means, standard deviations and correlations among variables are presented in Table 2. As shown in the table, high-level managers' ethical leadership was positively related to middle-level supervisors' ethical efficacy $(r=.56, p<.01)$ and unethical behavior-punishment expectation $(r=.38, p<.01)$. Additionally, middle-level supervisors' ethical efficacy $(r=.62, p<.01)$ and unethical behavior-punishment expectation $(r=.51, p<.01)$ were positively related to their ethical leadership (aggregated from subordinates' ratings). In what follows, we develop a multilevel model to test the hypotheses.

Insert Table 2 about here

\section{Hypotheses Testing}

Hypothesis 1 predicted that high-level managers' ethical leadership would be positively related to the middle-level supervisors' ethical leadership. Before testing this hypothesis, we examined whether there was significant between-group variance in subordinates' perceived ethical leadership of middle-level supervisors. The results 
revealed a significant between-group variance $\left(\sigma^{2}=0.21, \tau^{00}=0.19, \chi^{2}=404.69, p<.01\right.$; ICC (1) $=.48$, indicating that $48 \%$ of the variance can be attributed to level 2$)$, justifying the appropriateness of the use of hierarchical linear modeling to test the hypotheses.

To test H1, we estimated an intercepts-as-outcomes model in HLM 6.08, in which we used high-level managers' ethical leadership (level 2 predictor) to predict the intercept of middle-level supervisors' ethical leadership (level 1 outcome). As shown in Table 3, after controlling for middle-level supervisors' age, gender, education and position tenure, high-level managers' ethical leadership related positively to middle-level supervisors' ethical leadership $(B=0.40, p<.01)$. Thus, Hypothesis 1 was supported.

Insert Table 3 about here

Hypotheses 2 to 4 proposed that middle-level supervisors' three ethical expectations (level 2) would mediate the relationship between high-level managers' ethical leadership (level 2) and middle-level supervisors' ethical leadership (level 1). We tested these three mediation effects simultaneously in the same multilevel path-analytical model, in which there were three level-2 paths linking high-level managers' ethical leadership and middlelevel supervisors' three ethical expectations (path $a_{1}, a_{2}$, and $a_{3}$, respectively), and another three level-1 paths linking middle-level supervisors' ethical expectations and ethical leadership (path $b_{1}, b_{2}$, and $b_{3}$, respectively). The proposed mediation effects were examined by estimating the three indirect effects linking high-level managers' ethical 
leadership and middle-level supervisors' ethical leadership: $a_{1} b_{1}, a_{2} b_{2}$, and $a_{3} b_{3}$, respectively. As shown in Table 4, the indirect effect of high-level managers' ethical leadership on middle-level supervisors' ethical leadership through middle-level supervisor's ethical efficacy expectation was 0.13 , with a 95\% Monte Carlo CI being $[0.01,0.26]$, which did not include zero, suggesting that the indirect effect was significant, supporting $\mathrm{H} 2$. The indirect effect through unethical behavior-punishment expectation was also significant (estimate $=0.09,95 \%$ Monte Carlo CI $[0.01,0.18]$ ). Thus, Hypothesis 4 was supported. However, the indirect effect through ethical behaviorreward expectation was not significant (estimate $=-0.02,95 \%$ Monte Carlo CI [-0.07, 0.01]), which did not support H3.

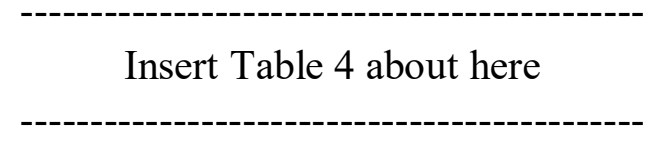

\section{DISCUSSION}

Although past research has recognized the trickle-down effect of ethical leadership, the underlying mechanism delineating the cascading process still remains largely unclear. Building upon social learning theory, which suggests that a role model influences an observer's behaviors through shaping his or her cognitive expectations (Bandura 1977; Manz and Sims 1981), we proposed and tested an integrative dual-process model in which the trickle-down effect of high-level managers' ethical leadership on middle-level supervisors' ethical leadership was mediated by middle-level supervisors' cognitive 
expectations about their ethical efficacy and the potential outcomes of their ethical or unethical behaviors. Results from a survey study of 69 middle-level supervisors and 381 subordinates from a large banking company largely supported the model we proposed. We discuss the implications, limitations, and future directions of our findings as follows.

\section{Theoretical Implications}

First, through exploring the mediating roles of ethical expectations, we disentangled the intermediate psychological processes underlying the trickle-down effect of ethical leadership. Resonating with several recent studies on ethical leadership (Mayer et al. 2009; Ruiz et al. 2011a, b; Schaubroeck et al. 2012), our study also revealed a positive relationship between high-level managers' ethical leadership and middle-level supervisors' ethical leadership, providing further support for this trickle-down effect of ethical leadership. Going beyond that, the significant mediating effects of ethical expectations as we found in the current study, clearly delineated the underlying mechanism of how ethical leadership cascades downward in an organization. Specifically, we found that high-level managers' ethical leadership could facilitate middle-level supervisors' exhibition of ethical leadership behaviors through influencing their ethical efficacy expectation and unethical behavior-punishment expectation. According to social learning theory, efficacy expectation and outcome expectation are the two major cognitive processes influencing human functioning (Bandura 2012; Manz and Sims 1981). Our research extended the expectation-related perspectives of social learning 
theory into the ethical leadership context, and thus provided a novel and meaningful understanding of the social learning process of ethical leadership. As theorized in the current study, ethical efficacy expectations instill followers with a "can-do" motivation for their ethical behavior regulations, while ethical outcome expectations instill them with a "reason-to-do" motivation. The findings of our research, to some extent, provided direct support for the well-recognized social learning account of the trickle-down effect of ethical leadership.

Second, we contributed to the growing, yet still limited, body of literature on ethical efficacy. To explain an individual's ethical behaviors, earlier studies have highlighted the importance of moral judgment (Blasi 1980; Kohlberg 1969). The association between moral judgment and ethical behaviors, however, remains weak and inconsistent. This is also called as the "judgment-action gap" (Jennings et al. 2015; Walker 2004). As such, an individual's judging a situation as ethical or unethical and understanding of what should be done and what should not be done does not necessarily translate into ethical behaviors. In this sense, understanding how to motivate ethical behaviors is critically important (Treviño et al. 2006). Defined as individuals' beliefs about their abilities to execute ethical behaviors, ethical efficacy is a relevant construct that could help address the “judgment-behavior gap” (Hannah and Avolio 2010; Hannah et al. 2011; Mitchell and Palmer 2010; Sweeney et al. 2015). However, despite its close relevance with ethical behaviors, insofar only a few studies have investigated the role of ethical efficacy in the 
ethics domain. For instance, Schaubroeck et al. (2012) found that ethical leadership could influence followers' ethical efficacy through ethical culture. Lee et al.'s (2015) recent research found that followers' ethical efficacy could mediate the effect of ethical leadership on followers' moral voice behaviors. By providing support for the intermediary role of ethical efficacy in the trickle-down process of high-level managers' ethical leadership, the current research added to the ongoing exploration of ethical efficacy in the organizational ethics context, advancing the knowledge of ethical efficacy's antecedents and consequences. However, it should also be noted that the research on ethical efficacy is still in its infancy, and thus more research is needed to further the understanding of this construct.

Third, we contributed to the research on ethical outcome expectation by extending it to the area of ethical leadership. Despite its important role in the regulation of moral behaviors (Ashkanasy et al. 2006; Treviño and Youngblood 1990), expectations of ethical outcomes received little attention from researchers. Drawing on earlier work by Treviño and Youngblood (1990), we took a pioneering step to differentiate two important types of ethical outcome expectations: the expectation of getting rewards for ethical behaviors, and the expectation of getting punished for unethical conducts. Furthermore, we found evidence supporting the intermediary role of middle-level supervisor's unethical behavior-punishment expectation in the cascading process of high-level managers' ethical leadership, which suggested that ethical leaders could influence their 
followers to become ethical leaders through shaping their expectations that behaving unethically would be punished. However, the study lent no support to the mediating effect of ethical behavior-reward expectation. We argue that there might be three possible reasons for this unsupported effect. First, prior research suggested that, in the short term, using rewards to elicit ethical behaviors may be frustrating. As posited by Treviño and Brown (2004, p.79), "Can we really reward ethical behavior? In the short term, we probably cannot. For the most part, ethical behavior is simply expected, and people don't expect or want to be rewarded for doing their jobs the right way". Second, it has been posited that a transactional leadership approach, characterized by managing by exception and contingent reinforcement, is more likely to draw followers' attention to oughts, duties and losses (Kark and van Dijk 2007), thus making them more sensitive to behaviors that they should not do. Given that ethical leaders usually use a transactional approach to hold followers accountable (Brown et al. 2005; Treviño and Brown 2014), it could be reasoned that supervisors working under ethical managers might pay more attention to losses, such as punishments for behaving unethically, rather than to gains, such as rewards for behaving ethically. In indirect support of our finding, Shao et al. (2011) suggested that ethical leadership is more likely to induce employees' ethical prevention focus, a construct that to some extent is similar to unethical behavior-punishment expectation. Finally, the unsupported mediating role of ethical behavior-reward expectation might also be attributed to the measurement of ethical leadership in the 
current research. Although Brown et al. (2005) contended that ethical leaders use rewards and punishments to hold followers accountable for their conducts, the Ethical Leadership Scale (Brown et al. 2005; Detert et al. 2007) we used only captured the "punishment" component (e.g., disciplining employees who violate ethical standards), yet neglected the "reward" component.

Fourth, as a reply to a recent study by Wo et al. (2015), the present study defended the legitimacy of using social learning theory to explain trickle-down effects in organization studies. Wo et al. explored the mechanisms underlying the cascading process of interactional justice perception through three perspectives: social learning, social exchange, and displaced aggression. Through two studies, they found no support for the social learning perspective, thereby casting doubt on its validity in explaining the trickle-down effect. Responding to their call for a re-evaluation of the social learning perspective, we used ethical efficacy expectation and ethical outcome expectation, two core variables rooted in social learning theory, to examine the validity of this theory in explaining the cascading effect of ethical leadership. Based on our findings, the current research defended the legitimacy of using social learning theory in explaining the trickledown effect. Indeed, different theories may have different power in explaining the trickledown process of an organizational phenomenon. According to our observations, when studying the trickle-down effect of behaviors (e.g., leadership behaviors, citizenship behaviors, creativity), researchers primarily used social learning theory (e.g., Jaussi and 
Dionne 2003; Li and Sun 2015; Liu et al. 2012; Yaffe and Kark 2011); when explaining the trickle-down effect of exchange relationships (e.g., leader-member exchange, perceived organizational support) or justice perceptions (e.g., Aryee et al. 2007; Tepper and Taylor 2003; Venkataramani et al. 2010), social exchange theory was mostly used; the displaced aggression perspective is mainly adopted to account for the cascading effect of negative leaderships (e.g., abusive supervision) and injustice perception (e.g., Aryee et al. 2007; Hoobler and Brass 2006; Tepper et al. 2006). Taken together, it could be reasoned that social exchange theory and displaced aggression perspective might have stronger power than social learning theory in explaining the trickle-down effect of justice perceptions, as examined in Wo et al.'s study; yet when it comes to the cascading effect of ethical leadership behaviors, social learning theory might be a more suitable perspective.

Finally, from the results of our data analyses, we found some effects relating to the control variables of our study interesting and we believe these small yet interesting findings could indicate potential research questions to be examined in the future. As was shown in Table 3, supervisor gender was positively $(B=.27, p<.05)$ associated with their ethical efficacy expectation, such that females tend to have higher ethical efficacy scores than males. Given that existing research suggested that women should be more likely to conduct ethical behaviors and avoid unethical behaviors than men (see Franke et al. 1997; Kish-Gephart et al. 2010; Pan and Sparks 2012 for meta-analytical reviews) and 
men are more than two times as likely as women to engage in actions regarded as unethical (Betz et al. 1989), the finding that women have higher belief in their ability to execute ethical behaviors is not surprising. Besides, supervisor's level of education was negatively $(B=-.36, p<.05)$ related to supervisors' ethical behavior-reward expectation yet positively $(B=.22, p<.05)$ associated with supervisors' unethical behaviorpunishment expectation. A possible explanation could be that those highly educated people, due to their higher levels of morality or their higher levels of conscience, may view conducting ethical behaviors as something normal in their life. Under this circumstance, they may not expect any rewards for their good deeds and sometimes, they might even dislike the rewards given for good deeds. However, in terms of unethical behaviors, highly educated individuals might be more likely to have a strong belief in norms or principles, which essentially requires a punishment for unethical behaviors.

\section{Practical Implications}

This research also has practical implications for organization management, especially for the ethics management in the banking industry where ethical scandals have happened so frequently and have caused severe consequences. First, consistent with other explorations of trickle-down effects of leadership, the present study highlighted the importance of the role modeling of leadership and indicated that high-level leaders should set examples for middle-level supervisors in the practice of ethical leadership. Moreover, supervisors can act either as transmitters of ethical behaviors or as inhibitors of unethical 
behaviors due to their role as linking-pins in the organization. Therefore, the role of middle-level supervisors in promoting the trickle-down effect of ethical behaviors should deserve greater attention in organizational ethics management. Second, our findings of the intermediate mechanisms underlying the trickle-down effect offered deeper insights into how the trickle-down effect occurs, providing practical recommendations for facilitating the trickle-down effect. For instance, high-level managers should serve as ethical role models for middle-level supervisors to bolster their perceived abilities to execute ethical behaviors and to shape their ethical outcome expectations, which would in turn transform those supervisors into ethical leaders.

\section{Limitations and Future Directions}

Our research is not without limitations. First, although we have theoretically delineated the causal relationships among variables, the cross-sectional data used in the current study still limited us in making causal inferences. The use of multi-source ratings in the current study could help alleviate the common method variance to some extent, yet future research could use more advanced design to provide more conservative and robust support for the proposed relationships among variables. For example, a multi-wave longitudinal design with the ratings for ethical leadership and the mediators separate in time would help establish more robust findings. Second, in this study we only collected our sample from the banking industry, the generalizability of our findings to other contexts remains to be further investigated. Although ethical leadership research does not 
primarily focus on any specific sector, or generate conclusions that were only applicable to any given sector. Future research should still consider the generalizability of the trickle-down effect to other research settings. Third, in theorizing on the proposed mechanisms linking manager's ethical leadership and followers' ethical efficacy expectation, we relied heavily on social learning theory and suggested that the four sources of efficacy, as suggested originally by Bandura (1977), to be the focal determinants of ethical efficacy. However, due to the lack of a valid scale, we did not measure the four sources of efficacy directly in the current study, which is an obvious limitation of our study. This said, future research should develop a reliable and valid scale to measure the four sources of efficacy.

The fourth limitation concerned with the use of self-developed measure of ethical outcome expectations. As suggested by Bandura (1977), outcome expectation is very specific to the research context. Bearing this in mind, we indeed tried to find an existing measure for ethical outcome expectations. Although there have been a few studies that operationalized ethical outcome expectations (Ashkanasy et al. 2006; Treviño and Youngblood 1990), the measurement approach used in these studies, either designed for an experimental setting or based on a general assessment (i.e., not differentiating two types of expectations), did not fit well with the context and the purpose of our research. Given the lack of an appropriate scale to measure ethical outcome expectations, we considered the alternative of using a self-developed measure instead. We realized that, 
however, many researchers have developed measures according to their research purposes. For instance, Yuan and Woodman (2010) developed 3 items to assess employees' expected positive performance outcomes from innovative behaviors; Lian et al. (2011) developed a 5-item scale to assess employees' perceptions of the likelihood that abusive behaviors would be rewarded; Schaubroeck et al. (2016) recently used a selfdeveloped 3-item scale to evaluate employees' beliefs about the benefits of engaging in desired customer service behaviors. In light of these studies, we built upon our theorizing of ethical outcome expectations and developed a 6-item measure for the current study. Although the self-developed measure has demonstrated good reliability and validity, we still encourage future research to further develop and validate a rigorous measure for ethical outcome expectations.

Finally, we examined the trickle-down effect of ethical leadership and its "black box" solely from the social learning perspective, leaving other potential perspectives uncharted. The theories of ethical leadership and the earlier work on the trickle-down effect of leadership in combination suggested that there may be more than one reason explaining why ethical leadership cascades in organizations. For instance, according to social exchange theory and the observation that "imitation is the sincerest form of flattery" (Liden et al. 2014, p.1436), middle-level supervisors are expected to feel a sense of indebtedness to high-level ethical managers because of their trustworthy, humane, and fair nature (Mayer et al. 2012), and such a sense of indebtedness might drive middle-level 
supervisors to reciprocate ethical managers by emulating their ethical leadership behaviors. Besides social exchange theory, social identity theory may also be an alternative explanation. This theory holds that followers who identify with their leaders are more sensitive to and active in meeting leaders' expectations (Aron 2003; Li and Sun 2015; Pratt 1998). In this sense, it could be possible that high-level managers' ethical leadership could elicit middle-level supervisors' personal identification with managers (e.g., Walumbwa et al. 2011), which would in turn influence them to display behaviors that are consistent with high-level managers' ethical expectations. This said, future research should continue investigating alternative explanations for the trickle-down effect of ethical leadership, which could help provide a more comprehensive understanding of this phenomenon. 


\section{NOTE}

${ }^{1}$ Consistent with the common practices in the management field (e.g., Mitchell and Palmer 2010; Treviño et al. 2006), we used the terms ethical and moral interchangeably in this paper.

${ }^{2}$ The MLQ (copyright 2010 by Sean T. Hannah and Bruce J. Avolio) was used with the permission of Mind Garden, Inc. All rights reserved.

\section{COMPLIANCE WITH ETHICAL STANDARDS}

Ethical approval: All procedures performed in this study were in accordance with the ethical standards of the institutional research committee and with the 1964 Helsinki declaration and its later amendments or comparable ethical standards.

Informed consent: Informed consent was obtained from all individual participants included in this study. 


\section{REFERENCES}

Aron, A. (2003). Self and close relationships. In M. R. Leary \& J. P. Tagney (Eds.), Handbook of self and identity (pp. 442-461). New York: The Guilford Press.

Aryee, S., Chen, Z. X., Sun, L. Y., \& Debrah, Y. A. (2007). Antecedents and outcomes of abusive supervision: Test of a trickle-down model. Journal of Applied Psychology, 92(1), 191-201.

Arnaud, A., \& Schminke, M. (2012). The ethical climate and context of organizations: A comprehensive model. Organziaiton Science, 23(6), 1767-1780.

Ashkanasy, N. M., Windsor, C. A., \& Treviño, L. K. (2006). Bad apples in bad barrels revisited: Cognitive moral development, just world beliefs, rewards, and ethical decision making. Business Ethics Quarterly, 16(4), 449-473.

Bandura, A. (1977). Social learning theory. Englewood Cliffs, NJ: Prentice-Hall. Bandura, A. (1991). Social cognitive theory of moral thought and action. In W. M. Kurtines \& J. L. Gewwirtz (Eds.), Handbook of moral behavior and development (pp. 45-103). Hillsdale, NJ: Lawrence Erlbaum.

Bandura, A. (1997). Self-efficacy: The exercise of control. New York: Freeman.

Bandura, A. (2012). On the functional properties of perceived self-efficacy revisited. Journal of Management, 38(1), 9-44. 
Bedi, A., Alpaslan, C. M., \& Green, S. (2015). A meta-analytic review of ethical leadership outcomes and moderators. Journal of Business Ethics. doi: $10.1007 / \mathrm{s} 10551-015-2625-1$.

Betz, M., O'Connell, L., \& Shepard, J. M. (1989). Gender differences in proclivity for unethical behavior. Journal of Business Ethics, 8(5), 321-324,

Blasi, A. (1980). Bridging moral cognition and moral action: A critical review of the literature. Psychological Bulletin, 88(1), 1-45.

Bliese, P. D. (2000). Within-group agreement, non-independence, and reliability: implications for data aggregation and analysis. In K. J. Klein \& S. W. Kozlowski (Eds.), Multilevel theory, research, and methods in organizations (pp. 349-381). San Francisco: Jossey-Bass.

Boatright, J. R. (2010). Finance ethics: Critical issues in theory and practice. Hoboken, NJ: Wiley.

Brown, M. E., \& Treviño, L. K. (2006). Ethical leadership: A review and future directions. Leadership Quarterly, 17(6), 595-616.

Brown, M. E., \& Treviño, L. K. (2014). Do role models matter? An investigation of role modeling as an antecedent of perceived ethical Leadership. Journal of Business Ethics, 122(4), 587-598. 
Brown, M. E, Treviño, L. K., \& Harrison, D. A. (2005). Ethical leadership: A social learning perspective for construct development and testing. Organizational Behavior and Human Decision Processes, 97(2), 117-134.

Brislin, R. W. (1986). The wording and translation of research instruments. In. W. J. Lonner \& J. W. Berry (Eds.), Field methods in cross-cultural research (pp. 136-164). Newbury Park, CA: Sage.

Davis, T. R. V., \& Luthans, F. (1980). A social learning approach to organizational behavior. Academy of Management Review, 5(2), 281-290.

den Hartog, D. N. (2015). Ethical leadership. Annual Review of Organizational Psychology and Organizational Behavior, 2, 409-434.

Detert, J. R., Treviño, L. K., Burris, E. R., \& Andiappan, M. (2007). Managerial modes of influence and counterproductively in organizations: A longitudinal businessunit-level investigation. Journal of Applied Psychology, 92(4), 993-1005.

Fischbach, S. (2015). Ethical efficacy as a measure of training effectiveness: An application of the graphic novel case method versus traditional written case study. Journal of Business Ethics, 128(3), 603-615.

Fornell, C., \& Larcker, D. E (1981). Evaluating structural equation models with unobserved variables and measurement error. Journal of Marketing Research, $18(1), 39-50$. 
Franke, G. R., Crown, D. F., \& Spake, D. F. (1997). Gender differences in ethical perceptions of business practices: A social role theory perspective. Journal of Applied Psychology, 82(6), 920-934.

Hannah, S. T., \& Avolio, B. J. (2010). Moral poteny: Building the capacity for characterbased leadership. Consulting Psychological Journal: Practice and Research, $62(4), 291-310$.

Hannah, S. T., Avolio, B. J., \& May, D. R. (2011). Moral maturation and moral conation: A capacity approach to explaining moral thought and action. Academy of Management Review, 36(4), 663-685.

Hoobler, J., \& Brass, D. (2006). Abusive supervision and family undermining as displaced aggression. Journal of Applied Psychology, 91(5), 1125-1133.

James, L. R., Demaree, R. J., \& Wolf, G. (1993). Rwg: An assessment of within-group interrater agreement. Journal of Applied Psychology, 78(2), 306-309.

Jaussi, K. S., \& Dionne, S. D. (2003). Leading for creativity: The role of unconventional leader behavior. Leadership Quarterly, 14(4-5), 475-498.

Jennings, P. L., Mitchell, M. S., \& Hannah, S. T. (2015). The moral self: A review and integration of the literature. Journal of Organizational Behavior, 36(S1), S104-S168. 
Kark, R., \& Van Dijk, D. (2007). Motivation to lead, motivation to follow: The role of the self-regulatory focus in leadership processes. Academy of Management Review, 32(2), 500-528.

Kish-Gephart, J. J., Harrison, D, A., \& Treviño, L. K. (2010). Bad apples, bad cases, and bad barrels: meta-analytic evidence about sources of unethical decisions at work. Journal of Applied Psychology, 95(1), 1-31.

Kohlberg, L. (1969). Stage and sequence. The cognitive developmental approach to socialization. In D. Goslin (Ed.), Handbook of socialization theory (pp. 347480). Chicago: RanMcNally.

Hofmann, D. A., \& Gavin, M. B. (1998). Centering decisions in Hierarchical Linear Models: Theoretical and methodological implications for organizational science. Journal of Management, 24(5), 623-641.

Lee, D., Choi, Y., Youn, S., \& Chun, J. K. (2015). Ethical leadership and employee moral voice: The mediating role of moral efficacy and the moderating role of leaderfollower value congruence. Journal of Business Ethics. doi:10.1007/s10551$015-2689-y$.

Li, Y., \& Sun, J. M. (2015). Traditional Chinese leadership and employee voice behavior: A cross-level examination. Leadership Quarterly, 26(2), 172-189. 
Lian, H., Ferris, D. L., \& Brown, D. J. (2011). Does power distance exacerbate or mitigate the effects of abusive supervision? It depends on the outcome. Journal of Applied Psychology, 97(1), 107-123.

Liden, R. C., Wayne, S. J., Liao, C. W., \& Meuser, J. D. (2014). Servant leadership and serving culture: Influence on individual and unit performance. Academy of Management Journal, 57(5), 1434-1452.

Liu, D., Liao, H., \& Loi, R. (2012). The dark side of leadership: A three-level investigation of the cascading effect of abusive supervision on employee creativity. Academy of Management Journal, 55(5), 1187-1212.

Manz, C. C., \& Sims, H. P. (1981). Vicarious learning: The influence of modeling on organizational behavior. Academy of Management Review, 6(1), 105-113.

May, D. R., Luth, M .T., \& Schwoerer, C. E. (2013). The influence of business ethics education on moral efficacy, moral meaningfulness, and moral courage: A quasi-experimental study. Journal of Business Ethics, 124(1), 67-80.

Mayer, D. M., Aquino, K., Greenbaum, R. L., \& Kuenzi, M. (2012). Who displays ethical leadership and why does it matter? An examination of antecedents and consequences of ethical leadership. Academy of Management Journal, 55(1), 151-171. 
Mayer, D. M., Kuenzi, M., Greenbaum, R., Bardes, M., \& Salvador, R. (2009). How low does ethical leadership flow? Test of a trickle-down model. Organizational Behavior and Human Decision Processes, 108(1), 1-13.

Mitchell, M. S., \& Palmer, N. F. (2010). The managerial relevance of ethical efficacy. In M.Schminke (Ed.), Managerial ethics: Managing the psychology of morality (pp. 89-108). New York: Routledge.

Muthén, L. K. \& Muthén, B. O. (1998-2012). Mplus user's guide (7th ed). Los Angeles: Muthén \& Muthén.

Ng, T. W., \& Feldman, D. C. (2015). Ethical leadership: Meta-analytic evidence of criterion-related and incremental validity. Journal of Applied Psychology, $100(3), 948-965$.

Pan, Y., \& Sparks, J. R. (2012). Predictors, consequence, and measurement of ethical judgments: Review and meta-analysis. Journal of Business Research, 65(1), 84-91.

Pratt, M. G. (1998). To be or not to be: Central questions in organizational identification. In D. A. Whetton \& P. C. Godfrey (Eds.), Identity in organization: Building theory through conversations (pp.171-208). Thousand Oaks, CA: Sage.

Raudenbush, S. W., \& Bryk, A. S. (2002). Hierarchical linear models: Applications and data analysis methods. Newbury Park, CA: Sage. 
Ruiz, P., Ruiz, C., \& Martínez, R. (2011a). Improving the "leader-follower" relationship: Top manager or supervisor? The ethical leadership trickle-down effect on follower job response. Journal of Business Ethics, 99(4), 587-608.

Ruiz, P., Ruiz, C., \& Martínez, R. (2011b). The cascading effect of top management's ethical leadership: Supervisors or other lower-hierarchical level individuals?. African Journal of Business Management, 5(12), 4755-4764.

Ruiz-Palomino, P., Martínez-Ruiz, M. P., \& Martínez-Cañas, R. (2013). Assessing ethical behaviours in the Spanish banking and insurance industries: Evidence and challenges. International Journal of Human Resource Management, 24(11), 2173-2196.

Ruiz-Palomino, P., Ruiz-Amaya, C., \& Knörr, H. (2011). Employee organizational citizenship behaviour: The direct and indirect impact of ethical leadership. Canadian Journal of Administrative Sciences, 28(3), 244-258.

Schaubroeck, J. M., Hannah, S. T., Avolio, B. J., Kozlowski, S. W. J., Lord, R. G., Treviño, L. K., Dimotakis, N., \& Peng, A. C. (2012). Embedding ethical leadership within and across organization levels. Academy of Management Journal, 55(5), 1053-1078.

Schaubroeck, J. M., Lam, S. S. K., \& Peng, A. C. (2016). Can peers' ethical and transformational leadership improve coworkers' service quality? A latent 
growth analysis. Organizational Behavior and Human Decision Processes, 133(1), 45-58.

Selig, J. P., \& Preacher, K. J. (2008). Monte Carlo method for assessing mediation: An interactive tool for creating confidence intervals for indirect effects [Computer software]. Available from http://quantpsy.org/.

Shao, P., Resick, C. J., \& Schaubroeck, J. (2011). Ethical leadership and motivation: Examining promotion and prevention regulatory foci. Paper presented at the annual conference of the Academy of Management, San Antonio, TX.

Sims, R. R., \& Brinkman, J. (2002). Leaders as moral role models: The case of John Gutfreund at Salomon Brothers. Journal of Business Ethics, 35(4), 327-339.

Sumanth, J., \& Hannah, S. (2014). Developing leadership capacity: An integration and exploration of ethical and authentic leadership antecedents. In L.Neider \& C. Schriesheim (Eds.), Advances in authentic and ethical leadership (pp. 25-74). Charlotte, NC: Information Age Publishing.

Sweeney, P. J., Imboden, M. W., \& Hannah, S. (2015). Building moral strength: Bridging the moral judgment-action gap. New Directions for Student Leadership, 146, $17-33$.

Tepper, B. J., Duffy, M. K., Henle, C. A., \& Lambert, L. S. (2006). Procedural injustice, victim precipitation, and abusive supervision. Personnel Psychology, 59(1), $101-123$. 
Tepper, B. I., \& Taylor, E. C. (2003). Relationships among supervisors' and subordinates' procedural justice perceptions and organizational citizenship behaviors. Academy of Management Journal, 46(1), 97-105.

Treviño, L. K., \& Brown, M. (2004). Managing to be ethical: Debunking five business ethics myths. Academy of Management Executive, 18(2), 69-83.

Treviño, L. K., \& Brown, M. E. (2014). Ethical leadership. In D. V. Day (Ed.), The Oxford handbook of leadership and organizations. (pp. 524-538). Oxford: Oxford University Press.

Treviño, L. K., Brown, M., \& Hartman, L. P. (2003). A qualitative investigation of perceived executive ethical leadership: Perceptions from inside and outside the executive suite. Human Relations, 56(1), 5-37.

Treviño, L. K., den Nieuwenboer, N. A., \& Kish-Gephart, J. J. (2014). (Un)Ethical behavior in organization. Annual Review of Psychology, 65, 635-660.

Treviño, L. K., Weaver, G. R., \& Reynolds, S. J. (2006). Behavioral ethics in organizations: A review. Journal of Management, 32(6), 951-990.

Treviño, L. K., \& Youngblood, S. A. (1990). Bad apples in bad barrels: a causal analysis of ethical decision-making behavior. Jounal of Applied Psychology, 75(4), $378-385$. 
Venkataramani, V., Green, S. G., \& Schleicher, D. J. (2010). Well-connected leaders:

The impact of leaders' social network ties on LMX and members' work attitudes. Journal of Applied Psychology, 95(6), 1071-1084.

Walker, L. J. (2004). Gus in the gap: Bridging the judgment-action gap in moral functioning. In D. Lapsley \& D. N. Narvaez (Eds.), Moral development, self and identity (pp. 1-20). Mahwah, NJ: Lawrence Erlbaum.

Walumbwa, F. O., Mayer, D. M., Wang, P., Wang, H., Workman, K., \& Christensen, A. L. (2011). Linking ethical leadership to employee performance: The roles of leader-member exchange, self-efficacy, and organizational identification. Organizational Behavior and Human Decision Processes, 115(2), 204-213.

Walumbwa, F. O., \& Schaubroeck, J. (2009). Leader personality traits and employee voice behavior: Mediating roles of ethical leadership and work group psychological safety. Journal of Applied Psychology, 94(5), 1275-1286.

Weaver, G. R., Treviño, L. K., \& Agle, B. (2005). "Somebody I look up to": Ethical role models in organzations. Organizational Dynamics, 34(4), 313-330.

Weiss, H. M. (1977). Subordinate imitation of supervisor behavior: The role of modeling in organizational socialization. Organizational Behavior and Human Performance, 19(1), 89-105. 
Wo, D. X. H., Ambrose, M. L., \& Schminke, M. (2015). What drives trickle-down effects? A test of multiple mediation processes. Academy of Management Journal, 58(6), 1848-1868.

Yaffe, T., \& Kark, R. (2011). Leading by example: The case of leader OCB. Journal of Applied Psychology, 96(4), 806-826.

Yuan, F., \& Woodman, R. W. (2010). Innovative behavior in the workplace: The role of performance and image outcome expectations. Academy of Management Journal, 53(2), 323-342.

Yukl, G., Mahsud, R., Hassan, S., \& Prussia, G. E. (2013). An improved measure of ethical leadership. Journal of Leadership \& Organizational Studies, 20(1), 3848.

Zhang, Z., Zyphur, M. J., \& Preacher, K. J. (2009). Testing multilevel mediation using hierarchical linear models: Problems and solutions. Organizational Research Methods, 12(4), 695-719. 


\section{Appendix}

Items from the Six-Item Ethical Leadership Scale

1. Disciplines employees who violate ethical standards

2. Conducts his/her personal life in an ethical manner

3. Discusses business ethics or values with employees

4. Sets an example of how to do things the right way in terms of ethics

5. Defines success not just by results but also the way that they are obtained

6. When making decisions, asks "what is the right thing to do"

Note The above six-item ethical leadership scale was from Detert et al. (2007) and was adapted based on the original 10-item Ethical Leadership Scale (ELS) developed by Brown and colleagues (2005). 
Figure 1

\section{Research Model}

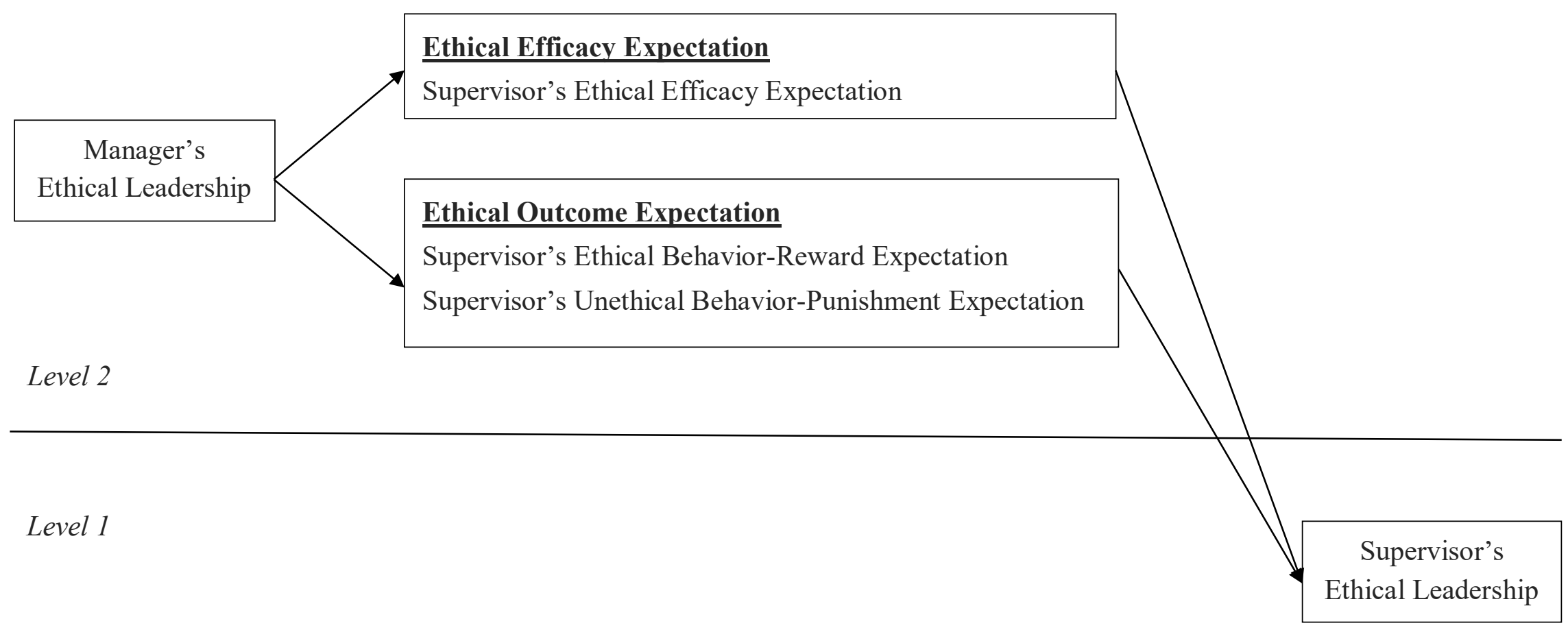


Table 1

\section{Results of Confirmatory Factor Analyses}

\begin{tabular}{|c|c|c|c|c|c|c|c|}
\hline Model & Factors & $\chi^{2}$ & $d f$ & $\Delta \chi^{2}$ & SRMR & $\mathrm{CFI}$ & TLI \\
\hline Model 0 & Theorized four factors. & 186.32 & 113 & & .08 & .93 & .91 \\
\hline Model 1 & $\begin{array}{l}\text { Three factors: ethical behavior-reward expectation and unethical } \\
\text { behavior-punishment expectation were merged as one factor } \\
\text { (ethical outcome expectation). }\end{array}$ & 259.78 & 116 & $73.46^{* *}$ & .14 & .88 & .86 \\
\hline Model 2 & $\begin{array}{l}\text { Two factors: ethical efficacy expectation, ethical behavior- } \\
\text { reward expectation and unethical behavior-punishment } \\
\text { expectation were merged as one factor (ethical expectation) }\end{array}$ & 365.83 & 118 & $179.51^{* *}$ & .13 & .80 & .77 \\
\hline Model 3 & One factor: all variables were merged as a single factor & 619.07 & 119 & $432.75^{* *}$ & .16 & .71 & .66 \\
\hline
\end{tabular}


Table 2

Means, Standard Deviations, and Correlations among Variables

\begin{tabular}{|c|c|c|c|c|c|c|c|c|c|c|c|}
\hline & $M$ & $S D$ & $\sqrt{ } \mathrm{AVE}$ & 1 & 2 & 3 & 4 & 5 & 6 & 7 & 8 \\
\hline 1. Supervisor age & 39.61 & 5.97 & - & & & & & & & & \\
\hline 2. Supervisor gender & 1.48 & 0.50 & - & -.04 & & & & & & & \\
\hline 3. Supervisor education & 2.99 & 0.44 & - & $-.35^{* *}$ & -.04 & & & & & & \\
\hline 4. Supervisor position tenure & 2.33 & 1.22 & - & $.40^{* *}$ & -.19 & -.02 & & & & & \\
\hline 5. Manager's ethical leadership & 3.99 & 0.67 & .84 & -.03 & .14 & -.05 & -.14 & & & & \\
\hline 6. Supervisor's ethical efficacy expectation & 3.88 & 0.62 & .82 & -.21 & $.31^{* *}$ & -.02 & -.23 & $.56^{* *}$ & & & \\
\hline 7. Supervisor's ethical behavior-reward expectation & 4.41 & 0.59 & .89 & -.22 & .05 & -.15 & -.01 & .19 & $.32^{* *}$ & & \\
\hline 8. Supervisor's unethical behavior-punishment expectation & 4.20 & 0.66 & .81 & -.01 & -.05 & .13 & .12 & $.38^{* *}$ & $.41^{* *}$ & $.41^{* *}$ & \\
\hline 9. Supervisor's ethical leadership (aggregated) & 4.12 & 0.49 & .92 & -.08 & .09 & .01 & -.14 & $.61^{* *}$ & $.62^{* *}$ & .15 & $.51^{* *}$ \\
\hline
\end{tabular}

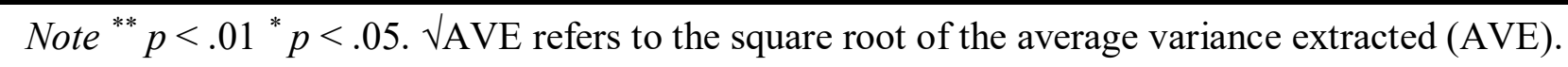


Table 3

Results of Cross-Level Regressions

\begin{tabular}{|c|c|c|c|c|c|}
\hline \multirow[b]{2}{*}{ Variables } & \multicolumn{5}{|c|}{ Mediators and Dependent Variables } \\
\hline & $\begin{array}{c}\text { Supervisor's } \\
\text { ethical } \\
\text { leadership }\end{array}$ & $\begin{array}{l}\text { Supervisor's } \\
\text { ethical } \\
\text { efficacy } \\
\text { expectation }\end{array}$ & $\begin{array}{c}\text { Supervisor's } \\
\text { ethical } \\
\text { behavior-reward } \\
\text { expectation }\end{array}$ & $\begin{array}{c}\text { Supervisor's } \\
\text { unethical behavior- } \\
\text { punishment } \\
\text { expectation }\end{array}$ & $\begin{array}{c}\text { Supervisor's } \\
\text { ethical } \\
\text { leadership }\end{array}$ \\
\hline \multicolumn{6}{|l|}{ Control variable } \\
\hline Supervisor age & -0.002 & $-0.02 \dagger$ & $-0.04^{*}$ & -0.002 & -0.001 \\
\hline Supervisor gender & -0.01 & $0.27^{*}$ & 0.03 & -0.09 & -0.06 \\
\hline Supervisor education & 0.04 & -0.07 & $-0.36^{*}$ & $0.22^{*}$ & -0.04 \\
\hline Supervisor position tenure & -0.02 & -0.03 & 0.08 & 0.09 & -0.02 \\
\hline \multicolumn{6}{|l|}{ Independent variable } \\
\hline Manager's ethical leadership & $0.40^{* *}$ & $0.47^{* *}$ & $0.17 \dagger$ & $0.41^{* *}$ & $0.21^{*}$ \\
\hline \multicolumn{6}{|l|}{ Mediators } \\
\hline Supervisor's ethical efficacy expectation & & & & & $0.27^{*}$ \\
\hline Supervisor's ethical behavior-reward expectation & & & & & -0.12 \\
\hline Supervisor's unethical behavior-punishment expectation & & & & & $0.21^{*}$ \\
\hline Level 2 Residual Variance & $0.12 * *$ & $0.23 * *$ & $0.29 * *$ & $0.35 * *$ & $0.09^{* *}$ \\
\hline
\end{tabular}

Note $B$ represents the unstandardized regression coefficients. $N_{\text {level } 2}=69, N_{\text {level } 1}=381$. Level 2 Residual Variance represents the unexplained variance at level 2 . The smaller the Level 2 residual variance, the greater amount of variance explained by the model.

${ }^{* *} p<.01 \quad{ }^{*} p<.05 \quad{ }^{\dagger} p<.10$. 
Table 4

Results of the Mediating Effects of Ethical Expectations

\begin{tabular}{lcccc}
\hline \multicolumn{1}{c}{ Indirect effects via } & \multirow{2}{*}{ Estimate } & $t$ test & \multicolumn{2}{c}{ Monte Carlo 95\% CI } \\
\cline { 4 - 6 } & & & Low End & High End \\
\hline Path 1: ethical efficacy expectation & 0.13 & $p=.048$ & 0.01 & 0.26 \\
Path 2: ethical behavior-reward expectation & -0.02 & $p=.299$ & -0.07 & 0.01 \\
Path 3: unethical behavior-punishment expectation & 0.09 & $p=.027$ & 0.01 & 0.18 \\
\hline
\end{tabular}

